\title{
A AVALIAÇÃO DA APRENDIZAGEM COMO UM ATO AMOROSO: 0 que o professor pratica?
}

\author{
Ana Lúcia Gomes Cavalcanti Neto* \\ Josefa de Lima Fernandes Aquino**
}

RESUMO: O estudo faz uma análise de concepções de professores da $3^{a}$ série do ensino fundamental II da cidade do Ribeirão/PE sobre avaliação da aprendizagem. A pesquisa, de caráter qualitativo, utilizou a entrevista semiestruturada como metodologia de coleta de dados. A análise desses dados, fundamentada nos princípios da avaliação como ato amoroso de mediação entre ensino e aprendizagem defendida por Luckesi, leva a concluir que, apesar da identificação de alguns elementos na ação pedagógica desses professores que representavam acolhimento, integração e inclusão, a significação de avaliação como momento pontual, classificatório e seletivo ainda é bastante evidente. Dessa forma, acredita-se que o caminho para uma real mudança nas concepções e, consequentemente, na ação pedagógica dos docentes está numa formação, tanto inicial quanto continuada, coerente com essa proposta pedagógica.

Palavras-chave: Avaliação da aprendizagem; Instrumento amoroso; Ensino- aprendizagem.

\section{EVALUATION OF THE LEARNING AS LOVING ACT: WHAT DOES THE TEACHER DO?}

ABSTRACT: The study makes an analysis of teachers' conceptions of the 3rd series of the fundamental teaching II of the city of Ribeirão/PE about evaluation of the learning. The research, of qualitative approach, used as collection methodology the semi-structured interview. The analysis of the data, based in the principles of the evaluation as loving act of mediation between teaching and learning protected by Luckesi, makes possible to us the conclusion of that in spite of the identification of some elements in those teachers' pedagogic action that represented reception, integration and inclusion, the evaluation significance as punctual, classificatory and selective moment is still quite evident. In that way we believe that the way to a real change in the conceptions, and consequently in those teachers' pedagogic action, is in a formation as much initial as continuous coherent with that pedagogic proposal.

Keywords: Evaluation of the learning; Loving tool; Teaching learning

* Mestre em Ensino de Ciências. E-mail: analuneto@gmail.com

** Graduada em Licenciatura em Pedagogia pela Faculdades da Escada (FAESC). 


\section{INTRODUCุÃO}

Diante das dificuldades que se impõem atualmente à melhoria da qualidade da educação, a avaliação destaca-se como um conjunto de conhecimentos imprescindíveis ao cotidiano docente, na medida em que se constitui como prática reflexiva do processo ensino e aprendizagem.

Nesse sentido, pensar em avaliação no contexto escolar significa pensar em tomada de decisões dirigidas a melhorar o ensino e, consequentemente, a aprendizagem dos alunos. Refletir sobre como direcionar a avaliação para esse caminho supõe pensar no objetivo de avaliar, perguntar-se sobre as funções da avaliação.

Luckesi (2005) destaca que o papel da avaliação é diagnosticar a situação da aprendizagem, tendo em vista subsidiar a tomada de decisão para a melhoria da qualidade do desempenho do educando. Nesse contexto, a avaliação, segundo o autor, é processual e dinâmica. $\mathrm{Na}$ medida em que busca meios pelos quais todos possam aprender o que é necessário para o próprio desenvolvimento, é inclusiva. Sendo inclusiva é, antes de tudo, um ato democrático.

O autor é enfático ao afirmar que o ato de avaliar, uma vez que está a serviço da obtenção do melhor resultado possível, implica a disposição de acolher a realidade como ela é, seja satisfatória ou insatisfatória, agradável ou desagradável. A disposição para acolher é, pois, o ponto de partida para qualquer prática de avaliação.

Nesse cenário, a avaliação da aprendizagem escolar é compreendida como um ato amoroso, "O ato amoroso é aquele que acolhe a situação, na sua verdade (como ela é)" (LUCKESI, 2005), é um estado psicológico oposto ao estado de exclusão. Como afirma Hoffmann (1993), "a avaliação é uma reflexão permanente sobre a realidade, e acompanhamento, passo a passo, do educando, na sua trajetória de construção de conhecimento". Dessa forma, o avaliador, por ser avaliador, não se assusta com a realidade, mas a observa atentamente; não a julga (aprova/reprova), mas se abre para observá-la, buscando conhecer essa realidade como verdadeiramente é, e, a partir dela, criar estratégias de superação dos limites e ampliação das possibilidades, com vistas à garantia da aprendizagem.

Luckesi (2005), com base no contraponto entre o que caracteriza a avaliação da aprendizagem e a observação das experiências vividas nas 
nossas escolas, considera que, em vez de avaliação, o que se pratica nas escolas são os exames, uma vez que as dificuldades apresentadas pelos alunos não são diagnosticadas para subsidiar uma intervenção adequada, mas são classificadas, tendo em vista a aprovação ou a reprovação. Para o autor, "a prática do exame, devido a operar com os recursos de aprovação/reprovação, obrigatoriamente conduz à política da reprovação, que tem se manifestado como o mais consistente álibi para o fracasso escolar" (LUCKESI, 2005, p. 19). Em avaliação não se julga nem se classifica, mas, sim, se diagnostica e se intervém em favor da melhoria dos resultados do desempenho dos educandos.

A abordagem de Hoffmann (1993) a respeito da contradição entre o que é falado e o que é praticado por alguns docentes indica que a ação classificatória e autoritária da avaliação é ainda exercida nas escolas. A autora ressalta que tal atitude está relacionada à concepção de avaliação do educador, reflexo de sua história de vida como aluno e como professor. Em relação a isso, Luckesi (2005, p. 30) faz a seguinte afirmação: "Em nossa vida escolar, fomos muito abusados com os exames (...)". “(...), hoje no papel de educadores, repetimos o padrão”.

Diante do exposto, podemos afirmar que o processo avaliativo tem relação direta com a significação que o professor construiu sobre avaliação da aprendizagem e que, em decorrência disso, a formação de uma concepção de avaliação como instrumento de comunicação que facilita a construção do conhecimento, como proposto por Luckesi, depende de uma coerente formação inicial e continuada dos mediadores do processo educativo.

Nesse cenário, a partir dessa reflexão e do entendimento de que uma prática educativa centrada na construção do conhecimento por parte do aluno e na interdependência do processo ensino e aprendizagem está diretamente ligada à concepção que o professor tem de avaliação é que se instaura a seguinte problemática: $\mathrm{O}$ professor da $3^{\mathrm{a}}$ série do ensino fundamental I compreende a avaliação como um instrumento amoroso de mediação entre ensino e aprendizagem?

Buscando respostas à problemática apresentada, nossa pesquisa objetiva analisar a significação de avaliação da aprendizagem apresentada pelos professores da $3^{a}$ série do Ensino Fundamental I de uma escola do Município do Ribeirão/PE. Para o cumprimento de tal objetivo procuramos identificar as concepções de professores sobre a avaliação da 
aprendizagem e identificar a relação estabelecida por eles entre avaliação e o processo ensino e aprendizagem.

\section{FUNDAMENTAÇÃO TEÓRICA}

Durante muito tempo, desde o estabelecimento da Didática como teoria de ensino, sistematizando o pensamento didático e o estudo científico das formas de ensinar, até o movimento escolanovista, a pedagogia enfocou o processo de ensino no professor acreditando que, dessa forma, estaria valorizando o conhecimento. Com isso, o processo de aprendizagem, dissociado do ensino, ficou relegado a segundo plano. Com o conhecimento acumulado, nas últimas décadas, em várias áreas do conhecimento que estudam o ser humano, e o consequente desenvolvimento das teorias construtivistas faz-se necessário ressignificar a unidade entre o ensino e a aprendizagem.

Nesse sentido, é certo que o aluno somente aprende se reconstruir conhecimento. Essa reconstrução se com base no que se já conhece dos saberes disponíveis e de nossa cultura (DEMO, 2004).

Nesse cenário, segundo Demo (2004), sendo a aprendizagem "dinâmica reconstrutiva" que ocorre de dentro para fora, não é a realidade externa que simplesmente se impõe ao sujeito, mas é ele que, no processo de aprendizagem, a capta de modo reconstrutivo, interpretativo ou hermenêutico. Nesse processo, o aluno, construtor do seu próprio conhecimento, não pode permanecer, no contexto educativo, escutando, copiando e devolvendo de modo reprodutivo na prova.

Partindo dessa reflexão, o professor tem papel importante no processo de aprendizagem, desde que possibilite ao aluno oportunidades para a reconstrução do conhecimento socialmente produzido. Em relação a isso, Demo (2004, p. 24) afirma que é "função precípua do professor cuidar da aprendizagem do aluno, com afinco, dedicação, continuidade e persistência". O autor é enfático, ainda, ao afirmar que o termo "cuidar" é enorme, complexo e contém a perspectiva humana da atenção emancipatória.

Buscando atender a tal perspectiva, não basta ao professor dar aulas. É preciso estar atento à situação individual de cada aluno. È preciso tirar a limpo, todos os dias, se seus alunos estão aprendendo.

É para contribuir com esse processo que a avaliação ocupa espaço essencial no conjunto das práticas pedagógicas aplicadas ao 
processo educacional, uma vez que possibilita aos envolvidos os dados sobre a realidade e o favorecimento das necessárias tomadas de decisão, no sentido de uma efetiva superação de dificuldades, com consequente garantia da aprendizagem.

Assim, com base no reconhecimento da avaliação como um processo pertencente à ação pedagógica, é importante caminhar em direção a uma reflexão a respeito da sua natureza acolhedora, interativa e inclusiva.

\section{AVALIAC̣ÃO DA APRENDIZAGEM ESCOLAR}

De forma geral, a avaliação da aprendizagem pode ser definida como um meio de que o professor dispõe de obter informações a respeito dos avanços e das dificuldades dos alunos, constituindo-se como um procedimento permanente, capaz de dar suporte ao processo de ensino e aprendizagem, no sentido de contribuir para o planejamento de ações que possibilitem ajudar o aluno a prosseguir, com êxito, no seu processo educacional.

Nesse sentido, Hoffmann esclarece:

O processo avaliativo não deve estar centrado no entendimento imediato pelo aluno das noções em estudo, ou no entendimento de todos em tempos equivalentes. Essencialmente, por que não há paradas ou retrocessos nos caminhos da aprendizagem. Todos os aprendizes estão sempre evoluindo, mas em diferentes ritmos e por caminhos singulares e únicos. $\mathrm{O}$ olhar do professor precisará abranger a diversidade de traçados, provocando-os a progredir sempre (HOFFMANN, 2001, p. 47).

Essa advertência a respeito dos caminhos da aprendizagem exige dos professores o cuidado no lidar com o espaço da escola, fazendo com que o aluno assuma um compromisso pessoal.

Para Vasconcellos (1998), a avaliação é um processo abrangente da existência humana que implica reflexão sobre a prática, no sentido de diagnosticar seus avanços e dificuldades e, a partir dos resultados, planejar tomadas de decisão sobre as atividades didáticas posteriores. Nesse contexto, a avaliação deveria acompanhar o aluno em seu processo de crescimento, contribuindo como instrumento facilitador da aprendizagem. 
Seguindo a mesma concepção, Hoffmann (2001) aponta a ação avaliativa como interpretação cuidadosa e abrangente das respostas do aluno frente a qualquer situação de aprendizagem, sendo necessário entendê-la como acompanhamento de uma trajetória.

De acordo com Furlan (2007), a avaliação só faz sentido se for utilizada com a finalidade de saber mais sobre o aluno e de colher elementos para que a educação escolar aconteça de forma próxima da realidade e dentro de um contexto.

Luckesi (2001), ao se referir às funções da avaliação, alerta para a importância de estarmos atentos à sua função ontológica, que é a de diagnosticar. Ela representa a base para uma coerente tomada de decisão, visto que se trata do meio de encaminhar os atos subseqüentes, na perspectiva de uma situação positiva em relação aos resultados almejados. Para Esteban (2001), a avaliação como prática de investigação pode ser uma alternativa às propostas excludentes por buscar uma ação coerente com a concepção de conhecimento como processo dinâmico, dialógico, fronteiriço, constituídos nos marcos das múltiplas tensões sociais.

Além de diagnosticar, a avaliação tem a função de propiciar a autocompreensão do nível e das condições em que se encontram tanto o educando quanto o educador. Esse reconhecimento do limite e da amplitude de onde se está possibilita uma motivação e a consequente contribuição tanto para auxílio quanto para o aprofundamento da aprendizagem.

Assim, é função da avaliação, de acordo com Furlan (2007), ajudar a construir a aprendizagem e a interferir ativamente em uma situação em curso. Para tanto, faz-se necessário conhecer o processo e perceber, na avaliação, indicadores de intervenção. De acordo com Silva (2004), quanto mais o professor conhecer as formas como os alunos aprendem, melhor será sua intervenção pedagógica.

Esse contexto nos leva a concluir que, sendo a avaliação um meio imprescindível para a aprendizagem, o processo educativo deve apontar para a construção de uma prática avaliativa qualitativamente mais significativa, comprometida com a aprendizagem e, consequentemente, com o crescimento pessoal e intelectual do educando. Nesse sentido, ela deve ser entendida como processo integrado com todas as outras atividades desenvolvidas pelo educando, as quais subsidiam a sua aprendizagem. Segundo Furlan (2007), o papel do professor nesse 
processo deve ser o de dar suporte à aproximação entre o que os alunos já sabem e o que necessitam saber. Diante disso, torna-se essencial ouvir o aluno, na busca da compreensão sobre o que ele pensa. É fundamental, de acordo com o autor, que o professor pense a respeito das características dos alunos e de como as considera ao planejar e ao executar ações pedagógicas.

\section{AVALIAĈ̣̃O: UM ATO AMOROSO DE MEDIAÇÃO NO PROCESSO ENSINO E APRENDIZAGEM}

O sentido original do termo mediação é intervenção, intercessão, intermediação. Explicando esse significado, Guiomar Namo de Mello diz que:

Mediação refere-se ao que está ou acontece no meio, ou entre duas ou mais coisas separadas no tempo e/ou no espaço (...) o movimento se realiza por mediações que fazem a passagem de um nível a outro, de uma coisa a outra, de uma parte a outra, dentro daquela realidade. (MELLO, 1985, p. 24-25)

Se transferirmos essas considerações para a ação de avaliar, poderemos vislumbrá-la nessa perspectiva, ou seja, a ação avaliativa, enquanto mediação, se faria presente, justamente, no interstício entre uma etapa possível de produção pelo aluno e de um saber enriquecido, de um saber complementado.

Nesse contexto, a avaliação da aprendizagem é defendida por Luckesi (1995) como um ato amoroso, no sentido de que a avaliação, por si, é um ato acolhedor, integrativo, inclusivo. A avaliação, portanto, não está no fim, como resultado da aprendizagem, selecionando os mais aptos, mas, sim, o sujeito aprende, se forma, se constrói porque a avaliação está no interior do ato educativo, é ela que garante que o processo de aprender se efetive e é esse processo que torna o aluno sujeito na "feitura" de si mesmo. Para isso, é necessário entender a avaliação como possibilidade de vir a ser ou fazer um outro de si mesmo, a construção de cada um e do coletivo como diferentes, saudáveis, alegres, cidadãos. É a prática da nossa existência se construindo com base na avaliação que fazemos de nós mesmos e das incorporações que fazemos a partir da percepção-atuação do outro conosco, de tal forma assim como 
sofremos a interferência do outro, também interferimos na realidade do outro. Portanto, a formação da identidade se dá no encontro com o outro, numa construção social, e não como algo meramente objetivo e natural. O caráter da avaliação tem, assim, outra dimensão. É diferente, pois propicia avanço, progressão, mudança e a criação do novo.

"O ato de avaliar, devido a estar a serviço da obtenção do melhor resultado possível, antes de tudo, implica a disposição de acolher a realidade como ela é" (LUCKESI, 2005). Isso significa a possibilidade de tomar uma situação da forma como se apresenta, seja ela satisfatória ou não. Acolhê-la, como está, é o ponto de partida para se fazer qualquer coisa que possa ser feita com ela. Sem esse acolhimento da realidade como ela se apresenta, não existe possibilidade de uma intervenção adequada, pois qualquer outro ponto de partida seria enganoso e sem sustentação, segundo o autor.

Conduzir a avaliação nesse contexto implica reflexão crítica sobre a prática, no sentido de diagnosticar seus avanços e dificuldades e de possibilitar uma tomada de decisões sobre as "iniciativas cabíveis. Portanto, avaliar não é apenas constatar, mas, sobretudo analisar interpretar, tomar decisões e reorganizar o ensino" (SILVA, 2002).

De acordo Furlan (2007), Hoffmann aponta a ação avaliativa como interpretação cuidadosa e abrangente das respostas do educando frente a qualquer situação de aprendizagem, sendo necessário entendê-la como acompanhamento de uma trajetória, permeada pelo entendimento e pela troca de ideias entre todos os participantes da ação educativa.

Portanto, nesse contexto, avaliar um educando implica, antes de qualquer coisa, acolhê-lo no seu ser e no seu modo de ser, como está, para, então, a partir daí, decidir o que fazer. Diante disso, concordamos com Luckesi (1995) ao afirmar que a avaliação é um ato amoroso. "O ato amoroso é aquele que acolhe a situação, na sua verdade (como ela é)”. Por acolher a situação como ela é, o ato amoroso tem a característica de não julgar. Julgamentos aparecerão, todavia, para dar curso à vida (à ação), e não para excluí-la. Para Luckesi:

$\mathrm{Na}$ avaliação nós não precisamos julgar, necessitamos isto sim, de diagnosticar, tendo em vista encontrar soluções mais adequadas e mais satisfatórias para os impasses e dificuldades. Para isso, não é necessário nem ameaça, nem castigo, mas sim acolhimento e confrontação amorosa. (LUCKESI, 2005, p. 33) 
De acordo com o autor, a disposição de acolher a realidade faz parte da conduta do avaliador, e não do objeto da avaliação. Para isso, ele deve ter a disposição de acolher. Sem essa disposição por parte do avaliador, não há avaliação. Essa disposição implica disponibilidade à realidade. Não é possível avaliar um educando, se este, desde o início, for excluído. Não há nada que se possa fazer com o que foi recusado. Para Luckesi,

Essa é uma prática que exige de cada um de nós educadores: vínculo com a profissão, formação adequada e consistente, compromisso permanente com a educação, atenção plena e cuidadosa com todas as nossas intervenções, a flexibilidade no relacionamento com os educandos. (LUCKESI, 2005, p. 34)

Nessa perspectiva, em que a prática avaliativa aponta dados para a transposição didática do professor, justifica-se a afirmativa de que avaliação e ensino não se separam, contudo, não se confundem. A avaliação, assim como o ensino, tem seus atributos epistemológicos próprios (princípios, teorias, métodos, técnicas e instrumentos), sendo possível, portanto, ensinar informado por um paradigma e avaliar por outro.

Vale destacar, no entanto, que a sintonia entre as teorias de ensino, de aprendizagem e de avaliação tem se revelado um dos indicadores de qualidade de ensino, o que realça a necessidade de os professores se apropriarem dos fundamentos de suas práticas para ressignificá-las. O professor que conhece o que, por que, para que e como ensina, avalia e aprende tem mais condições de avaliar o seu trabalho, de reconstruí-lo e de elevá-lo a outro patamar de qualidade.

\section{AVALIAÇÃO OU EXAME: 0 QUE VEM SENDO PRATICADO?}

De acordo com Luckesi (1995), a prática escolar usualmente denominada avaliação da aprendizagem tem pouco a ver com avaliação. Ela é basicamente constituída de provas/exames. Na maioria das escolas, a ação do professor é limitada a transmitir e corrigir. O processo educativo se desenvolve em momentos estanques, sem elos de continuidade, desconectados em termos de progressão na construção do conhecimento.

As provas/exames, segundo o autor, no caso da aprendizagem escolar, têm por finalidade verificar o nível de desempenho do educando 
em determinado conteúdo e classificá-lo em termos de aprovação ou reprovação, por conceitos, notas ou algo semelhante. Manifesta-se, nesse contexto, uma prática seletiva, na qual aqueles que conseguem atingir os objetivos do professor são incluídos e os demais são excluídos.

A avaliação da aprendizagem realizada nesse contexto indica uma simples verificação quantitativa daquilo que o aluno aprendeu dos conteúdos abordados; avalia-se o resultado final, e não o processo; somente são levados em consideração os aspectos técnicos da avaliação. Essa forma de mensuração do aluno leva à desvalorização e à redução dos conceitos de avaliar, ocultando importantes reflexões sobre o processo de ensino e aprendizagem.

De acordo com Rabelo (2004), a avaliação exercida apenas com a função de classificar alunos não dá ênfase ao desenvolvimento e em pouco, ou em quase nada, auxilia no crescimento deles na aprendizagem.

Portanto, avaliar é muito mais do que aplicar um teste, uma prova, fazer uma observação, saber se um aluno merece esta ou aquela nota, este ou aquele conceito. Avaliar é um ato rigoroso de acompanhamento da aprendizagem. "É ela que permite tomar conhecimento do que se aprendeu e do que não se aprendeu e reorientar o educando para que supere suas dificuldades, na medida em que o que importa é aprender" (LUCKESI, 2005).

Todavia, faz-se necessário lembrar que "tentar uma prática de avaliação que objetive essa perspectiva virá, conseqüentemente, questionar todo o nosso modo de pensar e de agir, nossa consciência, nossa prática pedagógica e social, virá questionar a sociedade como um todo" (GUARESCHI citado por RABELO, 2004). De acordo o mesmo autor, tais questões envolvem mudanças filosóficas.

Nesse contexto, significa afirmar que conceitos e práticas que constituem a avaliação da aprendizagem só podem existir se estiverem articulados com uma pedagogia construtiva (LUCKESI, 2005), ou seja, articulados com uma pedagogia que esteja atenta ao ser humano como um ser em movimento, em construção permanente. 


\section{METODOLOGIA}

O estudo aqui relatado é resultado de uma pesquisa de caráter qualitativo. Segundo Sílvio Oliveira (citado por OLIVEIRA, 2008), as abordagens qualitativas facilitam descrever a complexidade de problemas e hipóteses, bem como analisar a interação entre variáveis, compreender e classificar determinados processos sociais, oferecer contribuições aos processos das mudanças, à criação ou à formação de opiniões de determinados grupos e à interpretação das particularidades dos comportamentos ou atitudes dos indivíduos.

Para este estudo foram selecionados quatro docentes da $3^{\mathrm{a}}$ série do ensino fundamental I que lecionam em uma escola municipal localizada na cidade do Ribeirão, em Pernambuco. Essa escola foi alvo de investigação das disciplinas de Prática de Ensino e Estágio. Os educadores foram antecipadamente informados dos objetivos da pesquisa e concordaram em participar, desde que fossem mantidos no anonimato. Portanto, para fins de sigilo, serão denominados, aqui, P1, P2, P3 e P4. Esses professores apresentam, respectivamente, a seguinte formação acadêmica: graduando em Letras, Licenciatura em Geografia, Licenciatura em História, graduando em Letras.

Para a coleta de dados, foi utilizada a entrevista semiestruturada. De acordo com Mazzotti e Gwandsznajder (2004), por sua natureza interativa, a entrevista permite tratar de temas complexos que dificilmente poderiam ser investigados adequadamente por meio de questionários, explorando-os em profundidade, podendo ser a principal técnica de coleta. Segundo os autores, nas entrevistas semiestruturadas, o entrevistador faz perguntas específicas, mas também deixa que o entrevistado responda em seus próprios termos.

Visando a atingir os objetivos propostos pela pesquisa, a entrevista, constituída por cinco questões, evidenciou os seguintes aspectos: concepção de avaliação; instrumentos utilizados na avaliação; procedimentos utilizados para informar aos alunos sobre o seu desempenho; momento da ação pedagógica; metodologia utilizada para trabalhar os conteúdos não-compreendidos pelos alunos; e evidências apresentadas pelos alunos que indicam que o processo de avaliação da aprendizagem melhorou o desempenho da sala de aula. As respostas obtidas foram analisadas à luz do referencial teórico já mencionado. 


\section{ANÁLISE DOS DADOS}

Em relação à concepção de avaliação, os professores deram as seguintes respostas:

Como sendo um processo de juízo de qualidade que muitas vezes no sistema tradicional pode ser injusto, mas se faz necessário, pois o sistema educacional louva o construtivismo, no entanto, nos deparamos com vestibulares e concurso cada vez mais sistemáticos. (P1)

Eu entendo que através da avaliação nós temos uma segurança da capacidade dos alunos, em certa parte, pois avaliação é feita todos os momentos em sala de aula. (P2)

É através da avaliação que sabemos a capacidade de cada aluno, por que a avaliação é feita todos os dias. (P3)

Sistema metódico que serve para medir um certo aprendizado. (P4)

Com base nas respostas apresentadas, fica evidente, pela fala de P1 e de P4, uma concepção de avaliação como mecanismo de classificação, por meio do qual os melhores alunos podem ser selecionados. Também é evidente que são instrumentos utilizados de forma pontual, em momentos predefinidos. Fica demonstrado, na resposta de P1, que o sistema do qual fazemos parte é contraditório em relação às políticas educacionais adotadas, sobretudo no que se refere à avaliação da aprendizagem no sistema escolar. Tal postura é resultado de uma formação baseada em métodos de avaliação que resultam na exclusão dos educandos, uma avaliação pautada na pedagogia do "a melhor escola é aquela que reprova”. Além dessa raiz, tal concepção é reforçada pela pressão dos sistemas governamentais, representada pela seleção dos vestibulares, concursos e entre outros. Esse tipo de pressão tem como consequência a resistência, por parte dos professores, em lançar um novo olhar para sua ação pedagógica, reforçando o que é apresentado por Libânio (1982), ao afirmar que a avaliação da aprendizagem é o âmbito da ação pedagógica em que os professores são mais resistentes.

Todavia, é importante ressaltar que essas concepções já vêm, por parte de muitos professores, sendo ressignificadas. Podemos perceber, com base nos dados apresentados, nas respostas de P2 e P3, evidências de 
um outro modelo de avaliação contrário ao que foi apresentado na análise anterior. Ao conceber avaliação como algo que dá segurança ao professor sobre a condição do aluno, suas potencialidades, os professores dão pistas de um tipo de avaliação coerente com o que é apresentado por Vasconcellos (1998). Este autor afirma que "avaliação implica reflexão sobre a prática no sentido de diagnosticar seus avanços e dificuldades e a partir dos resultados planejar tomadas de decisões". Isso nos leva a refletir sobre o papel da avaliação no contexto de sala de aula como o meio de que o professor dispõe para obter informações a respeito dos avanços e das dificuldades dos alunos, contribuindo para o refazer da ação pedagógica, no sentido de superação dessas dificuldades. Para que isso aconteça, a avaliação precisa ser um processo permanente, “(...) todos os aprendizes estão sempre evoluindo, mas em diferentes ritmos e por caminhos singulares e únicos" (HOFFMANN, 2001), e, por isso, ela deve ser desenvolvida considerando-se o tempo de aprendizagem de cada educando.

Em se tratando do questionamento feito sobre os instrumentos utilizados como avaliação, as respostas foram as seguintes:

Provas, exercícios, participação, comportamento e empenho individual. Lembrando que o mercado de trabalho e as instituições de ensino superior pedem a nota em uma prova. Temos que preparar o aluno para isso e não para o que seria bom, por exemplo, sua integração social e seu empenho. (P1)

As avaliações podem ser feitas oral, escrita e através das participações do aluno em sala de aula. (P2)

Trabalhos em grupo, individuais, provas orais e escritas, observações e cadernos, realizações de exercícios em classe ou em casa e observações dos alunos em classe. (P3)

A prova tradicional, pesquisas e trabalho em campo. (P4)

Os dados apresentados por P1, mais uma vez, reforçam a concepção de avaliação como instrumento que tem como função principal classificar os alunos. Podemos perceber, pela afirmação da professora, que a ação pedagógica é constituída de provas/exames. De acordo com Luckesi (1995), provas/exames têm a finalidade de verificar o nível de desempenho do educando em determinado conteúdo, com o 
fim de aprovação ou reprovação. Tal prática tem como consequência a exclusão. A resposta de $\mathrm{P} 4$ com relação à utilização da prova tradicional como instrumento de avaliação nos leva a concluir que, mesmo utilizando outros instrumentos de avaliação, sua ação pedagógica está centrada em um processo de avaliação seletivo, como o defendido por P1.

Considerando as respostas apresentadas por P2 e P3 à questão relacionada à concepção de avaliação e fazendo um paralelo com as atividades utilizadas pelas docentes nas suas ações pedagógicas, percebemos que, ainda que não esteja estabelecida uma concepção de avaliação nos moldes apresentados por Hoffmann (2001), Vasconcellos (1998) e Luckesi (1995), há uma tendência à mudança por partes desses educadores. A mudança não é fácil. "Tentar uma prática de avaliação que objetive essa perspectiva virá, consequentemente, questionar todo o nosso modo de pensar e de agir, nossa consciência, nossa prática pedagógica e social, virá questionar a sociedade como um todo" (GUARESCHI citado por RABELO, 2004), mas não é impossível, desde que se deseje e que se busque um fortalecimento teórico coerente.

Ao investigarmos sobre o procedimento utilizado para informar os alunos sobre o seu desempenho, obtivemos as seguintes afirmações:

Mostrando a eles o quanto eles são capazes de fazer cada exercício. (P2)

A conversa informal, depois a lousa, mostrando que eles são capazes de fazer cada exercício. (P3)

A partir das provas tradicionais, que ainda é um instrumento muito utilizado. (P4)

Percebemos, na resposta de P4, com a usual utilização da prova tradicional, que o diagnóstico das dificuldades do aluno ocorre em momentos estanques, pontuais e que tem como propósito verificar o nível de desempenho do educando em determinado conteúdo. Segundo Luckesi (1995), essa prática exclui uma parte dos educandos e admite como aceitos outra, manifestando-se, nesse caso, como uma prática seletiva.

Em relação às respostas obtidas de P2 e P3, percebemos uma preocupação com que os resultados alcançados pelos alunos possam contribuir, no sentido de possibilitar a eles o desejo de avançar, funcionando como elemento motivador para o crescimento. " $\mathrm{Na}$ medida 
em que ocorre o reconhecimento do limite e da amplitude de onde se está, descortina-se uma motivação para o prosseguimento no percurso de vida ou de estudo que se esteja realizando" (LUCKESI, 1995).

Em relação ao momento da ação pedagógica utilizado para trabalhar os conteúdos não-compreendidos pelos alunos:

Quando estou fazendo revisões gerais antes das provas, através das recuperações paralelas. (P1)

Dependendo do momento, sempre procurando fazer algo que chame a atenção dos alunos, com novas dinâmicas. (P2)

Quando os alunos estão bem atentos, começo a trabalhar os conteúdos que eles não entenderam procurando chamar sua atenção através de exercícios na lousa. (P3)

Quando os resultados não são bem aproveitados, reavaliamos e trabalhamos os erros. (P4)

Os dados apresentados por P1, a princípio, ao mesmo tempo em que demonstram preocupação com a aprendizagem dos alunos, deixam transparecer uma atitude de supervalorização do momento estanque, ou seja, da prova. Tal observação leva a concluir, mais uma vez, pela existência de uma postura, na ação pedagógica de P1, preocupada com a utilização da avaliação como fim, e não como meio, como é proposto por Luckesi (1995, 2005), Hoffman (2001) e Vasconcelos (1998).

No que se refere aos demais professores, os dados apontam para uma tendência em se trabalhar as dificuldades dos alunos durante o processo. Percebe-se na fala deles uma postura de acolhimento das dificuldades (não de julgamento) que os alunos apresentam, acolhimento no sentido de redirecionamento do processo, com o objetivo de atenuar as dificuldades. Essa ação pedagógica é amorosa. Segundo Luckesi (1995), o ato amoroso acolhe atos, ações, alegrias e dores como eles são. Nesse contexto, a avaliação é um ato amoroso, uma vez que se trata de um processo de acolher a realidade como ela aparece, sempre com o objetivo de possibilitar uma transformação positiva.

Ao tratar de quando e como os entrevistados percebem que o processo avaliativo melhorou o desempenho da sala de aula, as respostas foram: 
Primeiro, na participação da turma no assunto visto, segundo quando o assunto entre eles deixa de ser o costumeiro e passa a entrar o assunto visto. (P1)

Quando percebemos o interesse e a empolgação de cada um em querer fazer o melhor. (P2)

Quando percebemos o desejo dos alunos em fazer suas atividades de uma forma melhor. (P3)

Se existir uma troca dos conteúdos e participação em sala, percebe-se o melhoramento dos alunos, todavia, a participação em sala não quer dizer muito, observar cada aluno particularmente. (P4)

Considerando a avaliação da aprendizagem como um meio de que o professor dispõe para obter informações a respeito dos avanços e das dificuldades dos alunos, capaz de dar suporte ao processo de ensino e aprendizagem, e que a avaliação tem a função de motivar o crescimento, uma vez que ela "motiva na mesma medida em que diagnostica e cria o desejo de obter resultados mais satisfatórios" (LUCKESI, 1995), os dados coletados nas respostas de P2 e P3 demonstram uma preocupação, por parte deles, de que os educandos alcancem tal estado.

Em relação às respostas de P1 e P4, observa-se uma tendência à concepção do processo avaliativo como momento estanque, momento que privilegia conteúdos específicos de forma isolada. Tais práticas, segundo Luckesi (1995), "caracterizam provas/exames e implicam julgamento, com conseqüente exclusão”.

\section{CONSIDERACְÕES FINAIS}

O desenvolvimento deste estudo possibilitou um olhar investigador e diferenciado com relação à avaliação da aprendizagem no ambiente escolar, levando-nos a refletir sobre os reais objetivos da prática que faz parte da ação pedagógica.

Diante dos dados apresentados pelos professores investigados e buscando responder à problemática que norteou o desenvolvimento do estudo, podemos concluir que, apesar da identificação de alguns elementos, na ação pedagógica desses professores, que fundamentam a avaliação como um instrumento amoroso de mediação entre o ensino e a 
aprendizagem, a prática avaliativa continua apresentando caráter pontual, classificatório e excludente.

A avaliação da aprendizagem como processo contínuo deveria buscar diagnosticar as dificuldades do aluno e, de posse desse conhecimento, o professor deveria trabalhar de forma a propiciar a superação dessas dificuldades. Nesse sentido, a avaliação destaca-se como a própria ação educativa, que tem importante papel mediador no processo de ensino e aprendizagem, o qual não está fortemente presente nas concepções dos professores investigados.

Uma ação educativa que tenha como objetivo real a aprendizagem precisa considerar as reais necessidades dos atores do processo. Nesse sentido, a avaliação não pode ser conduzida como julgamento. $\mathrm{O}$ julgamento é um ato que distingue. A avaliação, nesse contexto, tem como essência diagnosticar. O diagnóstico inclui, uma vez que busca conhecer a realidade como ela se apresenta, tendo em vista oferecer possibilidades aos envolvidos, no sentido da superação das dificuldades.

Nesse contexto, o professor tem papel fundamental no processo avaliativo e, por isso, necessita, durante a ação educativa, buscar estimular e incentivar o aluno, com estratégias diferenciadas, possibilitando o acolhimento, a integração e a inclusão dos sujeitos do conhecimento. É imprescindível ao professor, no seu fazer cotidiano, dar oportunidade para os educandos trocarem ideias, se expressarem e participarem dos trabalhos em grupo e/ou individuais. Tal prática precisa estar pautada na harmonia, na união e no clima de afetividade entre educandos e educadores.

Entendemos que tudo isso exige uma mudança por parte dos educadores, todavia compreendemos que esse processo está diretamente relacionado tanto com o desejo desses educadores de quererem mudar quanto com uma formação inicial e continuada coerente, nas quais se objetive, sobretudo, questionar os modelos de avaliação excludentes, tão presentes nas nossas salas de aula, que, cada dia mais, vêm fortalecendo um modelo de sociedade também excludente.

Portanto, a partir destas reflexões, concluímos com a certeza cada vez maior do compromisso que temos, como profissionais da educação e seres sociais, planetários, em desenvolver práticas sustentadas na formação de pessoas mais humanas e solidárias e que só podem ser possíveis se fundamentadas em atos integradores, inclusivos e acolhedores. 


\section{REFERÊNCIAS}

ALVES-MAZZOTTI, Alda Judith; GEWANDSZNAJDER, Fernando. O método das ciências naturais e sociais: pesquisa quantitativa e qualitativa. 2 ed. São Paulo: Pioneira Thompson Learning, 2004.

BALLESTER, Margarita et al. Avaliação como apoio a aprendizagem. Porto Alegre: Artmed, 2003.

DEMO, Pedro. Ser professor é cuidar que o aluno aprenda. Porto Alegre: Mediação, 2004.

ESTEBAN, Maria Tereza. O que sabe quem erra? Reflexões sobre avaliação e o fracasso escolar. Rio de Janeiro: DP\&A, 2001.

FURLAN, Maria Inês Carlin. Avaliação da aprendizagem escolar convergências e divergências. São Paulo: Annablume, 2007.

HOFFMANN, Jussara. Avaliação mediadora: uma prática em construção da pré-escola à universidade. Porto Alegre: Educação \& Realidade, 1993.

HOFFMANN, Jussara. Avaliação mito e desafio: uma perspectiva construtivista. Porto Alegre: Educação \& Realidade, 1993.

LUCKESI, Cipriano Carlos. Avaliação da aprendizagem na escola: reelaborando conceitos e criando a prática. 2 ed. Salvador: Malabares Comunicações e eventos, 2005.

LUCKESI, Cipriano Carlos. Avaliação da aprendizagem escolar: estudos e proposições. São Paulo: Cortez, 1995.

OLIVEIRA, Maria Marly de. Projetos, relatórios e textos na educação básica: como fazer. Petrópolis/RJ: Vozes, 2008.

OLIVEIRA, Maria Marly de. Como fazer projetos, relatórios, monografias, dissertações e teses. 3 ed. Rio de Janeiro: Elsevier, 2005.

RABELO, Edmar Henrique. Avaliação: novos tempos, novas práticas. 7 ed. Petrópolis, RJ: Vozes, 1998.

SILVA, Janssen Felipe da. Avaliação do ensino e da aprendizagem numa perspectiva formativa reguladora. In: SILVA, Janssen Felipe da.; HOFFMANN, Jussara; ESTEBAN, Maria Tereza (Org.). Práticas avaliativas e aprendizagens significativas: em diferentes áreas do currículo. 3 Ed. Porto Alegre: Mediação, 2004.

SILVA, Janssen Felipe da. Avaliar... O quê? Quem? Como? Quando? In: Revista TV Escola, Brasília, MEC, outubro/novembro, 2002.

VASCONCELOS, Celso dos Santos. Avaliação da aprendizagem: práticas de mudanças. São Paulo: Libertad - Centro de Formações e Assessoria Pedagogia, 1998.

Recebido: 01/09/2008

Aprovado: 16/06/2009

Contato:

Faculdades da Escada (FAESC)

Rua Cel. Antonio Marques, 67 - Centro

Escada - E

CEP 55.500-000 